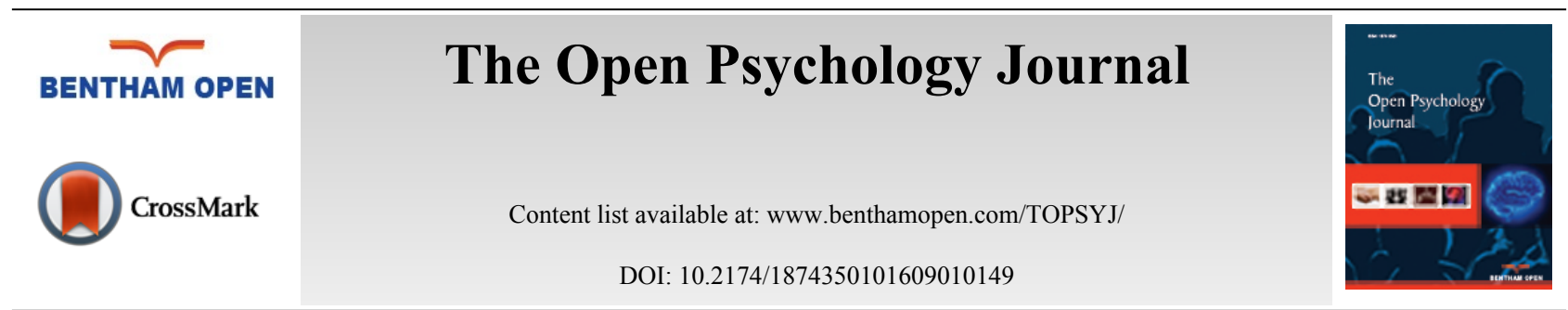

RESEARCH ARTICLE

\title{
Differences in Determinants of Indirect Perpetrator and Victim Behaviour
}

\author{
Marzanna Farnicka* \\ University of Zielona Góra, Institute of Psychology, Zielona Gora, Poland
}

Received: September 30, 2016

Revised: November 28, 2016

Accepted: December 05, 2016

\section{Abstract:}

\section{Background:}

Studies on young children indicate that victims of indirect peer aggression often terminate their relations with the perpetrators. This study is based on the social learning and learning theory approach. In this case adolescence is treated in a special period of changes in social functioning.

\section{Objective:}

The study presents specific determinants of indirect type of perpetrator and victim behaviour in adolescence. The study analyses the following determinants: aggressiveness, attachment and temperament.

\section{Method:}

The respondents' behaviour was measured with the self - assessment questionnaires: Mini DIA (Österman The Mini Inventory of Direct and Indirect Aggression, 2010), IPPA (Armsden, Greenberg Attachment scale, 1987), EAS (Buss, Plomin Temperament scale, 1997) and BPAQ (Buss, Perry Aggression Questionnaire, 1992).

The sample consisted of 160 secondary school students aged between 16 and 19 . There were 82 girls (60\%) and 78 boys (40\%) in the studied population. The study was conducted in groups during a one-hour session.

\section{Results:}

The research results indicated the significance of the nature of attachment (mother alienation) for the undertaken risky behaviour of both perpetrator-type and victim-type. The differences relate to the type of relationship with parents (secure or insecure pattern), own experience of being in the role of victim or perpetrator, and the level of hostility. A separate model of determining factors for indirect type of aggressive behaviour was also demonstrated.

\section{Conclusion:}

In the light of the presented results, the proper diagnostic process seems important in order to differentiate between the assumed roles (aggressor/victim) and to apply suitable measures. In the case of indirect-type aggressors, the focus should be on coping with hostility, self-control and emotional control skills and working on alternative ways of functioning in the family (particularly in the relationship with mother).

Keywords: Aggression, Adolescence, Attachment, Temperament.

\section{INTRODUCTION}

The classical definition of indirect aggression given by Björkqvist [1] says that it is 'a kind of social manipulation: the aggressor manipulates others to attack the victim or, by other means, makes use of the social structure in order to

* Address correspondence to this author at the University of Zielona Góra, Institute of Psychology, Zielona Gora, Poland; Tel: 0048500243681; Email:m.farnicka@wpps.uz.zgora.pl 
harm the target person, without being personally involved'. This definition and the later ones point out the existence of a relationship between the perpetrator and the victim, thus underlining its social nature. Archer [2] indicates the possibility of indirect aggression not only in the relationship dimension but also in the acts of indirect physical aggression (damaging property or good reputation of others). The authors [3] also emphasize that the problem with defining indirect aggression does not only exist in relation to research concerning children and adolescents, but also adults. Besides, lowering one's social status through manipulation or publishing insulting content on the Internet are not only jokes but actions that may have real consequences in the form of, for example, loss of job. Therefore, the controversies around indirect aggression have two causes. Firstly, this type of aggression utilizes various communication channels: a verbal one when one gossips or uses the Internet, for instance to write hateful comments or a physical one when one makes obscene gestures. Secondly, it usually refers to aggression in a relationship, e.g. between partners or in the parental context. In that case, we usually talk about an addressee, object, or victim (of jokes, stories or mails $[4,5]$.

Studies on young children indicate that the victims of indirect peer aggression often terminate their relations with the perpetrators. Thus, the applied aggression is supposed to change the victim's behaviour or terminate interactions [2]. In adolescence, aggressive behaviour may assume the form of bullying (in a direct or indirect form), through which a given person is isolated and belittled in the class either in a physical or verbal form, and also very often indirectly [6]. The relevant literature stresses that the goal of adolescent indirect aggression is not only to make the victim suffer in a relationship, but also to turn the victim's friends against him/her, or spread rumours about him/her [5 - 7]. A perpetrator or perpetrators may achieve this by spreading rumours, but also by sending e-mails or text messages, publishing video material on the Internet or engaging in 'hate'. It should be stressed that the perpetrator may be active, but s/he may also act in a passive manner, e.g. through limiting access to information or the possibility of certain information coming to light as a form of exclusion of a given person. In this approach one can point out that indirect aggression requires less effort than the traditional forms of confrontation, regardless of whether one remains in a personal relationship with the victim or not $[5,8]$.

The search for the determinants of aggressive behaviour and aggressiveness is difficult to describe due to its complex nature. The usually quoted determinants are of biological, social and situational types. Researchers who represent different approaches give different significance to particular factors depending on the adopted perspective. Numerous models of aggressive behaviour indicate temperament and other personality variables influencing selfregulation and emotional reactivity as significant risk factors for aggression [9 - 12]. Tendency to frustration is an aspect of emotional reactiveness and, as an element of negative effect (anger as a temperamental component), it influences impulse control and aggressive response in a situation of provocation $[12,13]$. In another research, Cloninger [14] stresses that other temperamental personality factors, such as; sensation seeking, may predestine one for criminal behaviour, parent and peer rejection and other behavioural problems (e.g. alcohol abuse or engaging in various forms of violence as a perpetrator).

Numerous studies indicate that the behaviour of caregivers in the first months of a child's life forms the foundations for the child's social abilities in the context of the development of aggressive behaviour [15]. In this sense, the ordering and intrapersonal characteristics of the child trigger an adequate reaction of his or her primary caregiver, and the mutual interaction becomes the foundation for the development of emotional and social competencies of the individual. There are many reasons for which hostile, rejecting or cold parenthood lead to the development of the child's personality towards aggressiveness. Children may learn aggressive behaviour and dysregulated response to stress from their caregivers. Insecure attachment patterns shaped in a direct relation with a close caregiver lead to perceiving others as hostile and untrustworthy [16], i.e. the development of views that are linked with the child's aggressiveness [5, 7, 17].

According to the General Model of Aggression [9] and own model of development of aggressiveness [18], aggression is largely based on the activation and application of aggression-related knowledge structures stored in past experiences and memory, recognition of a given situation as hostile, threatening or provocative, and on readiness for aggressive behaviour, which is connected with the physiological arousal, cognitive processes and aggression-related anger. Thus, activated readiness for aggression is subjected to decision-making processes as a result of which the individual reacts in an impulsive or reasoned manner. The new models based on the GAM indicate the role of the primary and secondary evaluation and identity as mediators during the appraisal and decision making processes [19].

The perspective of developmental psychopathology makes it possible to describe the mechanisms of mental disorder development and to explain the specifics of mental disorders in a lifecycle perspective. This approach takes into account the developmental and family dimensions, and it attempts to integrate knowledge from various fields (embryology, 
genetics, neurology, neuroscience, psychiatry, psychology) in order to understand the nature of the normal and impaired development [20 - 22]. The specificity of the approach is the search for the essence of selected disorders with particular emphasis on their sources and formation mechanisms by describing changes in their course and providing a multi-level developmental analysis of the sequence of healthy and disturbed behaviour ${ }^{1}[23,24]$.

Research undertaken from the perspective of developmental psychopathology has led to the discovery that development is conditioned on many levels and the formation of disorders should be considered from multiple perspectives (multiple-levels-of-analysis approach) [23]. From this perspective, possible disturbances in development are connected with numerous factors: temperament (impulsivity) [24] attachment [15, 25, 26], affective style [13, 28], previous experience of, for example, child maltreatment [28], or problems at school (lack of successes) [30], and influence of peers $[7,31]$. In the contextual framework, social context has an impact on development. The "toxic" social context is described as a low level of social resources. It means poverty, stigmatization, isolation and deviancy as cultural - social norms. From the perspective of an adaptation to a group, aggressive behaviour may be treated as maladaptation because it comes with its processes, which, in the social assessment, are considered unpleasant and sometimes dangerous to others. Usually, they stand at the crossroads of the individual needs and expectations of the group [32]. The analysis of the determinants for aggressive behaviour in active and passive forms confirms that many of them are connected with the development and persistence of aggressive behaviour in children and adolescents [33].

The present study verifies the assumptions concerning the role of personal traits of the individual (such as temperament, attachment and aggressiveness) in undertaking indirect aggressive behaviour and the perception of being a victim of indirect aggressive behaviour. The aim is to show the specific nature of factors determining the manifestations of the indirect type of aggressive behaviour in adolescence. The questions are focused on the recognition of determinants for undertaking the behaviour of indirect type (of both the victim and the perpetrator). The questions refer to the importance of selected dimensions of attachment, temperament and aggressiveness in the undertaken indirect aggressive behaviour of the perpetrator and victim type. The following research hypotheses were posed:

H1. Selected dimensions of attachment, temperament and aggressiveness are important to undertake indirect aggressive behaviour (both: the perpetrator and victim type).

The alienation as a dimension in attachment and temperamental anger and the level of aggressiveness will have positive impact on the frequency of undertaken indirect aggressive behaviour (victim and perpetrator type).

Factors connected with the origin and persistence of aggressive behaviour in children, adolescents and young adults are also sought in the disturbances of developmental processes in the biological, psychological and social sphere. The variables explained in the study (dependent variables) include:

- The construct called aggressiveness which characterizes the tendency to engage in aggressive behaviour in the future [35]. Aggressiveness is described as a personality trait that is conducive to uncontrolled, aggressive behaviour and the tendency to externalize problems. That trait is quite stable in time and persists as a special behavioural pattern from childhood to adolescence $[34,35]$.

- Temperament - the tendency to become frustrated is an aspect of emotional reactiveness and, as an element of negative affect (anger as a temperamental component), it influences impulse control and aggressive response in a situation of provocation [36]. In another research, Cloninger [14, 34] stresses that other temperamental personality factors, such as sensation seeking, may predestine one for criminal behaviour, parent and peer rejection and other behavioural problems (e.g. alcohol abuse or engaging in various forms of violence as a perpetrator). People diagnosed with the so-called "difficult temperament" are more prone to emotional dysregulation, a higher level of negative affect and a behavioural response to even a slight change in stimulation [12].

- Attachment - ordering and intrapersonal characteristics of the child trigger an adequate reaction of his or her primary caregiver, and the mutual interaction becomes the foundation for the development of emotional and social competencies of the individual. Insecure attachment patterns shaped in a direct relation with a close caregiver lead to the perception of others as hostile and untrustworthy [16], i.e. development of views that are linked with child and adolescent aggressiveness [17, 27, 37]. And although most studies concerning links between attachment and aggression in children are conducted in early and middle childhood, one should not

\footnotetext{
${ }^{1}$ Developmental psychopathology differs from psychopathology, whose main purpose is the description and classification of disorders, and from psychiatry whose goal is to provide effective assistance and therapy [20].
} 
disregard the fact that attachment plays an important role in shaping the behaviour of adolescents as well. Studies on childhood reveal increased aggressiveness in children with an insecure attachment pattern [5, 7, 29, 38].

- The frequency of undertaken victim or perpetrator type behaviour. The type of victim and perpetrator behaviour was seen as a frequency of behaviour undertaken as a result of specific social training in relationship and as a specific way of coping with social situations [3, 5, 39]. The individual who mostly assesses their functioning in the category of the victim is classified as the victim. The perpetrator is the individual who mostly describes their behaviour in the category of the perpetrator. In the sample, three groups were distinguished: one group of those who described themselves as perpetrators, one group of those who assessed themselves as victims, and one nonspecific group. The groups were characterized above.

\section{METHOD}

The sample consisted of 160 secondary school students aged between 16 and 19 . There were 82 girls $(60 \%)$ and 78 boys $(40 \%)$ in the studied population. The selection for the sample was purposive. The selection criterion was biological age ranging between 16 and 19. This criterion was chosen because of the changes taking place over that age period, concerning both psychological functioning and social relations connected with the realization of developmental tasks specific for that age. The study was conducted in groups during a one-hour session under the supervision of a school psychologist on randomly chosen classes of previously randomly chosen three secondary schools of the general education and vocational type. For underage students, parental consents were obtained. The difference between the number of boys and girls represented the actual ratio in the randomly chosen schools. The study was anonymous and voluntary.

\section{RESEARCH TOOLS}

Attachment was evaluated with the two subscales of the Inventory of Parent and Peer Attachment (IPPA) developed by Armsden and Greenberg [40]. This tool is to measure affective-cognitive patterns of attachment as the source of psychological security. The theoretical framework for IPPA is the attachment theory originally formulated by Bowlby and recently elaborated by other researchers. Four broad dimensions of attachment wereevaluated: attachment bond, level of mutual trust, quality of communication and extent of anger and alienation. Each scale contained 25 questions coded on the 5-point Likert scale from 1 which means "almost never or never true" to 5 - "almost always or always true". The obtained scores were within the range of 25 to 100 points, and for the particular subscales they are as follows: Attachment Bond and Trust 10-50, Communication 9-45, and Alienation 6-30. This is a self-report survey. Here are some questions in the Mother Version: trust: "My mother respects my feelings", or communication: "I like to get my mother's point of view on things I'm concerned about", "My mother helps me to talk about my difficulties" and alienation: and "Talking over my problems with my mother makes me feel ashamed or foolish". Cronbach's alpha reliability coefficients are as follows: Attachment Bond - Mother subscale 0.87, Attachment Bond - Father subscale 0.89. The psychometric validity tests produced satisfactory results.

Information about temperament was gathered with the EAS Temperament Survey by Buss and Plomin [41]. The version used was the self-descriptive version of EAS-D questionnaire for adults designed to assess the temperament of persons aged 13 and over. This version is a self-report survey. The EAS-D questionnaire included of 20 items constituting 5 scales: Distress (D) "I often feel frustrated", Fear (F) "I have more fears than others", Anger (A), "I am perceived as impetuous and short-tempered", Activity (Ac) "I like being busy" and Sociability (S) ("I like being with people"). Then, respondents gave their responses on a five-point scale ranging from 1 = "Definitely not, not typical" to 5 = "definitely yes, very typical”. Cronbach's alpha reliability coefficients remained within the range of 0.57-0.74.

The Aggression Questionnaire [42] was used to assess individual differences in aggressive personality. The 29-item scale is composed of four subscales: physical aggression ("Once in a while I can't control the urge to strike another person"), verbal aggression ("I tell my friends openly when I disagree with them"), anger ("When frustrated, I let my irritation show"), and hostility (I sometimes feel that people are laughing at me behind my back). Each scale is coded on the 5-point Likert scale from 1 = extremely uncharacteristic of me to $5=$ extremely characteristic of me. The sum of all scales is the basis to describe to the individual level of aggressiveness. Internal consistency for the four subscales and total score range from .72 (Verbal Aggression) to .89 (Total BPAQ score). Retest reliability for the BPAQ over nine weeks is also satisfactory (correlations ranged from .72 for Anger to .80 for Physical Aggression and for the total score). 
Information about aggressive/victim behaviour at school was gathered with the Mini Direct and Indirect Aggression Inventory (Mini-DIA). The Mini-DIA is an abbreviated version of the Direct-Indirect Aggression Scales [39], developed as a less time-consuming version of the original instrument. It has been shown to yield similar results as the original scales. It was a single-item scale and the types of aggression were defined to the respondents as follows: (1) physical aggression: "another pupil has for instance hit, kicked, or pushed you"; (2) verbal aggression: "another pupil has for instance screamed at you, or said hurtful things about you or your family"; (3) indirect aggression: "another pupil has spread malignant gossip about you, spread untrue stories about you, or tried to freeze you out". Then, the respondents give their responses on a five-point scale ranging from $0=$ "never" to $4=$ "often" to what extent they have been exposed to these. The maximum score for each scale was 12. Reliability for the Victim scale was .69 and .72 for the Perpetrator scale.

In order to evaluate the socio-demographic variables, a questionnaire was used to gather information about the age and sex of respondents, number of siblings, mother's family's financial situation (Table 1).

Table 1. The study group.

\begin{tabular}{|l|c|c|c|c|c|}
\hline & Minimum & Maximum & \multicolumn{2}{|c|}{ Mean Std. Error } & Std. Deviation \\
\hline Age & 16 & 19 & 17.68 & .21 & 2.31 \\
\hline Material status & 0 & 3 & 1.47 & .05 & .55 \\
\hline Siblings & 0 & 4 & 1.89 & .09 & .97 \\
\hline
\end{tabular}

In the sample the average number of siblings was two (91\%). Only children formed $6 \%$ of the total and families with 4 and more children accounted for 3\%. The family's financial status was evaluated as average by $44 \%$ of students, as poor by $53 \%$ and only $3 \%$ considered it as good. The predominant type of mother's education was secondary (38\%) and vocational (37\%), 20\% respondents' mothers had higher education level and 5\% primary education. Fathers predominantly had vocational school education $(42 \%)$ or secondary education $(40 \%)$, higher level of education was recorded for $14 \%$ of respondents, while $4 \%$ of them had fathers with primary education.

\section{RESULTS}

In the research, the relationship between gender, age and material status was analysed. Respondents who mainly assessed their behaviour in the category of the victim were qualified as victims. The group of perpetrators included those who assessed most of their behaviour in the category of the perpetrator. High scores for the perpetrator were less frequent than for the victim. The average score on the perpetrator scale was 3 but 4 on the victim scale (Table 2).

Table 2. Descriptive statistics of frequency of victim and perpetrator status and reliability of the scales.

\begin{tabular}{|l|c|c|c|c|c|c|}
\hline & Reliability & Minimum & Maximum & Mean & Std. Error & Std. Deviation \\
\hline mini victim & .69 & .00 & 11.0 & 4.05 & .23 & 2.46 \\
\hline mini perpetrator & .72 & .00 & 12.0 & 3.34 & .21 & 2.23 \\
\hline
\end{tabular}

In the study group, the perpetrator behaviour was undertaken more often than the victim behaviour. The group with higher sores in the victim status (experience) was represented by 35 respondents $(30 \%)$, and the perpetrator status by 30 respondents $(25 \%)$. The rest of the students were in non specific group (the medium in the standardized error or the same level of victim and perpetrator status - cf. Table 3 ).

Table 3. Distinguished groups by frequency of status perpetrator or victim.

\begin{tabular}{|l|c|c|c|c|c|c|}
\hline & \multicolumn{3}{|c|}{ Cluster } & \multirow{2}{*}{ df } & \multirow{2}{*}{ F } & \multirow{2}{*}{ p } \\
\cline { 2 - 5 } & Non specific & Victim's status & Perpetrator's status & & & \\
\hline Victim role & 2.24 & 6.63 & 4.39 & 2 & 81.881 & $<0.001$ \\
\hline Aggressor role & 1.95 & 3.20 & 6.25 & 2 & 83.401 & $<0.001$ \\
\hline $\mathrm{N}$ & 74 & 48 & 33 & & & \\
\hline
\end{tabular}

Cluster analyse.

The following dependencies related to socio-economic factors were observed in both groups ${ }^{2}$ : gender and variables such as mother's and father's education and the family material status (cf. Table 4).

\footnotetext{
${ }^{2}$ There was also a non-specific group that included individuals for whom the frequency of assessments in the category of the perpetrator or the victim was similar. Here the group was not included in the analysis
} 
Table 4. Differences between high victim and high perpetrator group (socio-economic variables).

\begin{tabular}{|c|c|c|c|c|c|}
\hline \multirow{3}{*}{$\begin{array}{|ll|} & \text { Variables } \\
\text { Sex in } \% & \\
\end{array}$} & \multicolumn{2}{|c|}{ Victim status } & \multicolumn{2}{|c|}{ Perpetrator status } & \multirow{2}{*}{$\begin{array}{c}\text { Significance } \\
\text { Kruskal- Wallis test }\end{array}$} \\
\hline & $\mathbf{F}$ & $\mathbf{M}$ & $\mathbf{F}$ & $\mathbf{M}$ & \\
\hline & 68.6 & 31 & 53.6 & 46.4 & chi $2=1.657, \mathrm{df}=2 \mathrm{p}=0.437$ \\
\hline Parents Education & Mother & Father & Mother & Father & \multirow[t]{2}{*}{ Mother $\operatorname{chi} 2=2.924, \mathrm{df}=2, \mathrm{p}=0.232$} \\
\hline Primary & 5.7 & 2.9 & 7.1 & 3.6 & \\
\hline Vocational & 48.6 & 50 & 35.7 & 48.1 & \multirow[t]{3}{*}{ Father chi $2=1.03, \mathrm{df}=2, \mathrm{p}=0.597$} \\
\hline Secondary & 34.3 & 35.3 & 32.1 & 33.3 & \\
\hline Higher & 11.4 & 11.8 & 25 & 14.8 & \\
\hline Evaluation of material status & & & & & chi $2=0.847, \mathrm{df} 2, \mathrm{p}=0.655$ \\
\hline Poor & \multicolumn{2}{|c|}{48.6} & \multicolumn{2}{|c|}{57.1} & \\
\hline Average & \multicolumn{2}{|c|}{48.6} & \multicolumn{2}{|c|}{42.9} & \\
\hline Very good & \multicolumn{2}{|c|}{2.9} & \multicolumn{2}{|c|}{0} & \\
\hline
\end{tabular}

$\mathrm{F}=$ female, $\mathrm{M}$ - male.

The analysis of determinants for undertaking the perpetrator/victim role pointed out the high significance of trust towards mother and towards both parents. No other significant differences between the groups were found in other dimensions of attachment, neither they were established in relation to age, number of siblings or other dimensions of attachment styles or the aggressiveness level (Table 5).

Table 5. Average scores and significance of differences for the remaining variables in both groups (age, attachment, and anger).

\begin{tabular}{|l|c|c|c|c|c|c|c|c|}
\hline & \multicolumn{3}{|c|}{ Victim profile } & \multicolumn{3}{c|}{ Perpetrator profile } & \multicolumn{2}{c|}{ Significance, df=2 } \\
\hline & X & SD & SE & X & SD & SE & F & p \\
\hline Age & 17.9 & 2.47 & .417 & 18.96 & 2.57 & .487 & 3.05 & .05 \\
\hline No. of siblings & 1.86 & .81 & .137 & 2.04 & 1.04 & .196 & 0.34 & .71 \\
\hline Trust Mother & 27.11 & 5.99 & 1.01 & 29.0 & 9.11 & 1.72 & 4.53 & .01 \\
\hline Trust Father & 26.48 & 10.39 & 1.81 & 24.64 & 8.43 & 1.68 & 1.30 & .27 \\
\hline Communication Mother & 12.57 & 2.98 & .504 & 13.86 & 4.17 & .788 & 1.34 & .26 \\
\hline Communication Father & 12.12 & 3.77 & .66 & 13.81 & 8.09 & 1.59 & 1.33 & .27 \\
\hline Alienation Mother & 21.31 & 4.74 & .80 & 22.07 & 4.35 & .82 & 0.4 & .67 \\
\hline Alienation Father & 19.52 & 5.69 & .99 & 22.64 & 12.99 & 2.59 & 1.23 & .29 \\
\hline Anger & 14.46 & 4.43 & .75 & 17.37 & 10.31 & 1.98 & 2.95 & .06 \\
\hline Hostility & 22.97 & 6.78 & 1.15 & 21.85 & 5.13 & .99 & 12.69 & .01 \\
\hline
\end{tabular}

\section{Undertaking Indirect Victim and Perpetrator Behaviour}

In order to recognise the determinants for undertaking indirect aggressive behaviour (of both victim and perpetrator type), the stepwise regression was used. The independent variables included: dimensions of attachment, temperament and aggressiveness. The analysis was carried out in the whole group.

In the case of indirect type victim status $\left(\mathrm{R}^{2}=.6, \mathrm{df}=4, \mathrm{~F}=9.54, \mathrm{p}<0001\right.$, regression analysis, method: hierarchic) the important prediction was noticed between: hostility $(\beta=-.11)$, temperamental fear $(\beta=.095)$, physical and verbal victim experience $(\beta=.2$, Table 6) But when age-related differences were included in the model, the model prediction rose to $\mathrm{R}^{2}=.242(\mathrm{df}=4, \mathrm{~F}=35.85, \mathrm{p}<0001)$. When taking age into account hostility ceased to be significant (see Table 6). This means that age is an important factor related to the frequency of assessing one's status as victims of indirect violence on the basis of one's experience (cf. Table 6).

Table 6. Predictors of indirect victim status.

\begin{tabular}{|c|c|c|c|c|c|c|c|}
\hline \multicolumn{8}{|c|}{ Coefficients $^{\text {a }}$} \\
\hline \multirow{2}{*}{\multicolumn{2}{|c|}{ Model }} & Standardized Coefficients & \multirow{2}{*}{$\mathbf{t}$} & \multirow{2}{*}{ Sig. } & \multicolumn{3}{|c|}{ Correlations } \\
\hline & & Beta & & & Zero-order & Partial & Part \\
\hline \multirow[t]{4}{*}{1} & (Constant) & & 4.42 & .0001 & & & \\
\hline & mini for victim verbal & .19 & 4.34 & .0001 & .19 & .20 & .19 \\
\hline & b-p hostility & -.11 & -2.39 & .02 & -.09 & -.11 & -.11 \\
\hline & temperamental fear & .09 & 2.07 & .04 & .11 & .09 & .09 \\
\hline
\end{tabular}




\begin{tabular}{|c|c|c|c|c|c|c|c|}
\hline \multicolumn{8}{|c|}{ Coefficients $^{\mathrm{a}}$} \\
\hline \multirow{2}{*}{\multicolumn{2}{|c|}{ Model }} & Standardized Coefficients & \multirow{2}{*}{$\mathbf{t}$} & \multirow{2}{*}{ Sig. } & \multicolumn{3}{|c|}{ Correlations } \\
\hline & & Beta & & & Zero-order & Partial & Par \\
\hline \multirow[t]{5}{*}{2} & (Constant) & & -6.01 & .00 & & & \\
\hline & mini for victim verbal & .18 & 4.32 & .00 & .19 & .20 & .18 \\
\hline & b- p hostility & -.03 & -.61 & .54 & -.09 & -.03 & -.03 \\
\hline & temperamental fear & .09 & 2.33 & .02 & .11 & .11 & .09 \\
\hline & age & .44 & 10.39 & .00 & .45 & .44 & .43 \\
\hline
\end{tabular}

${ }^{\mathrm{a}}$ Hierarchic regression analyse.

\section{Indirect Perpetrator Behaviour}

Being a perpetrator of indirect type aggression has got different determinants and is not in a relationship with typically understood aggressiveness $\left(\mathrm{R}^{2}=.263, \mathrm{df}=3, \mathrm{~F}=71.29, \mathrm{p}<.001\right)$. Significant predictors for perpetrator indirect behaviour were as follows: hostility $(\beta=.13)$, experience of being aggressor in verbal dimension $(\beta=.36)$ and experience of being victim of indirect aggression $(\beta=.25$, cf. Table 7). No other significant relations with age, gender or attachment were found.

Table 7. Predictors of indirect perpetrator status.

\begin{tabular}{|c|c|c|c|c|c|c|c|}
\hline \multicolumn{8}{|c|}{ Coefficients $^{\text {a }}$} \\
\hline \multirow{2}{*}{\multicolumn{2}{|c|}{ Model }} & \multirow{2}{*}{$\begin{array}{c}\text { Standardized Coefficients } \\
\text { Beta }\end{array}$} & \multirow[t]{2}{*}{$\mathbf{t}$} & \multirow[t]{2}{*}{ Sig. } & \multicolumn{3}{|c|}{ Correlations } \\
\hline & & & & & Zero-order & Partial & Part \\
\hline \multirow[t]{4}{*}{1} & (Constant) & & 1.38 & .17 & & & \\
\hline & b- p hostility & .13 & 3.41 & .001 & .13 & .15 & .13 \\
\hline & mini for victim indirect & .25 & 6.29 & .001 & .35 & .26 & .24 \\
\hline & mini for perpetrator verbal & .36 & 9.18 & .001 & .44 & .37 & .34 \\
\hline
\end{tabular}

${ }^{2}$ Hierarchic regression analyse, standardized coefficients.

\section{DISCUSSION}

In the presented study the evaluation was carried out of the following personality traits: temperament, attachment and aggressiveness level. It also included indirect victim and perpetrator type behaviour on the basis of the frequency of assuming the indirect victim or perpetrator role.

The gender effect in aggressiveness (gender- aggressiveness $-\mathrm{df}=1, \mathrm{t}=25.4, \mathrm{p}<.001$, $\mathrm{t}$ - student test) and the age effect in undertaking aggressive behaviour $(\mathrm{df}=10, \mathrm{~F}=2.06, \mathrm{p}<.05$, Anova) were noticed. Data concerning differences connected with gender and socialization were described by Björkqvist, Lagerspetz \& Österman [43] and Busching and Krahé [44] and related to the frequency of assuming specific types of aggressive behaviour in adolescence. The analysis of other sociodemographic factors such as a number of siblings and perceived material status did not prove significant for assuming the perpetrator or victim role. This result confirms previous research by Renken, Egeland, Marvinney, Mangelsdorf, Sroufe [45], who noticed lack of correlation of aggressiveness and attachment with the family material status. However, the protective function of age in victim-type behaviour was demonstrated. This is the result that is concordant with the assumptions about the development of control functions in adolescence and may indicate their significance [46].

The obtained results reveal the difference between the construct of 'being a victim of indirect aggression', which appears to be more linked to the psychological state of hostility (in the Buss-Perry dimension), and temperamental fear. The results of previous studies into the relationship between aggressiveness, temperament and attachment with undertaken aggressive behaviour (of both victim and perpetrator type) reveal that victim-type behaviour remains in weak positive correlation with the measured level of temperamental anger and the general level of aggressiveness and it negatively correlates with age. Thus, the obtained results indicate that the frequency of undertaking the victim role increases along with the experienced frequency of being a verbal aggression victim ${ }_{2}$ the perpetrator of physical aggression and felt temperamental fear. It should be noted that the significance of perceiving reality in terms of hostility decreases with age. It can be stated that the discovered dependencies are related to giving oneself the status of indirect violence victim more frequently with age. Another interesting and worth mentioning thing is the negative relationship between hostility and the status of the victim attributed to oneself. Individuals with lower hostility often perceive themselves as victims of indirect violence. The obtained results are consistent with the assumptions of the significance 
of temperamental fear and socialization experiences related to violence. And although the level of parents' education seems to be significant in the differentiation of groups it did not hold a significant role in the obtained regression models.

The construct of "being a perpetrator" is more linked to the earlier manifested acts of verbal aggression and being a victim of indirect aggression. This means that the frequency of undertaken indirect perpetrator-type behaviour increases along with the hostility and own previous experience. In this case it may be concluded that the downward spiral of aggressiveness and subsequent aggressive acts might exist.

\section{The Construct of Aggressiveness and Indirect Behaviour}

A noteworthy result of the presented study is the relationship between the dimensions of aggressiveness and undertaking the role of indirect perpetrator and victim. In both cases hostility was important but in opposite correlation. Its negative correlation with the indirect victim status and positive correlation with indirect perpetrator status seem to be significant.

The study results also fit into the context of discussions on the role of control and own decisiveness at the moment of arousal. That result indicates that the feeling of hostility may be important for the ability to cope with emotional states and it points to the cause of cognitive disturbances that may appear both in a victim and in a perpetrator at the moment of interpreting stimuli from a given situation. It should be remembered that hostility relates to emotional and cognitive structures and facilitates the activation of cognitive patterns connected with protective reactions [10, 12, 13, 47]. The obtained results indicate the significance of mental processes and states as well as behaviour fixed in cognitive patterns at the moment of making a decision about the type of behaviour to be undertaken in a given situation. Those experiences may both decide on a quicker and more frequent access to certain behaviour but also become a source of self-knowledge and the basis for creating one's self-image influencing the emerging personality [34, 48, 49]. Those states may be caused by stimuli, but may also be habitual.

The role of age. Due to the fact that the described research related to adolescents and the role of age in the victim status, the developmental characteristics of that life period should be taken into consideration. Young people can change and reconstruct their style of functioning. Developmental changes were connected with gaining control over physiological arousal, stronger cognitive control, the ability to foresee the consequences of one's behaviour, and the creation of one's own image. Therefore, the respondents could present themselves as victims more often than as perpetrators. From this perspective, behaviour which is described as aggressive is not a manifestation of "the most effective strategy." but a manifestation of "helplessness in dealing with internal conflicts and interpersonal relationships". Both existing conflicts and the consequences of behaviour can lead or can be a source of growth disorders. They can hinder or even inhibit the personality development of the individual (emotional deregulation. changing self-image, group isolation etc.).

On the other hand, individuals experiment (often under peer influence) with new ways of reacting and behaving in situations that are new and stressful for them and learn to adjust to the expectations of the peer group in order to get accepted or gain a higher position. The critical nature of adolescence and the oscillation between "power and helplessness' were pointed out by Obuchowska [50]. The mechanisms available for that age group to cope with threats have two ways: a passive one: consisting of escaping, and an active one: concentrated on searching. In adverse circumstances both mechanisms may cause an escape 'from this world' or fight 'with this mean world'. If those coping strategies are adopted, the mechanism will manifest itself in the attitude of resignation or aggression. Thus, the results obtained from individuals who are in this special transition period should be viewed as a manifestation of the ongoing process of building their own identities and defining themselves in various situations.

\section{LIMITATION SECTIONS}

The study presented in this paper have two main limitations: the nature of the researched processes as well as the way of conducting the study and its plan.

It has been assumed that independent variables are ontogenetically primary to aggressiveness, and therefore might influence its development and intensity. It is possible that in the course of personality development, those variables become mutually correlated.

In the adopted research plan, comparisons refer to one moment and are of cross-cohort type .A better picture of the examined changes and their developmental trajectories in time could have been obtained and developed if a longitudinal 
plan was adopted.

Moreover, the study included one - homogeneous group of individuals who did not have problems with their behavior in a way that exceeded the developmental and cultural standards in a given society. If the sample had included young people from risk groups who had problems in this area, a deeper picture of the significance of the observed relations might have been obtained.

\section{CONCLUSION}

The research results revealed separate determinants for indirect-type perpetrators. These determinants differ in nature from other perpetrator-type ones and may be more strongly connected with the feeling of rejection or insecure attachment patterns. The research findings suggest that assuming the indirect perpetrator role or the victim role are two separate ways of coping with difficult social situations. The main differences are connected with temperamental fear and role of hostility. Another issue resulting from the study is the possible existence of a downward spiral of aggressive behaviour, exposure to violence and experiencing violence in other than indirect dimensions. The results may also indicate that at least in the case of the development of indirect behaviour, it can be observed that the victim status and the perpetrator status are two sides of the same coin. Recent reports on indirect violence indicate changes that have taken place in relation to the age of respondents, forms and functions of displayed behaviour and its motives. The forms of indirect aggression change due to availability of various channels of interpersonal communication. Moreover, it changes along with the individual's development and activity in various life contexts.

In the light of the presented results, the proper diagnostic process seems important in order to be able to predict the possibility of assuming the status of victims and perpetrators of indirect violence on the basis of hostility and temperamental fear.

The conclusions for practice indicate the essential role of temperament and the importance of coping with emotions and cognitive mistakes in attribution and the exposure to behaviour that violates the limits at all levels of communication: physical, verbal, and indirect ones.

\section{CONFLICT OF INTEREST}

The authors confirm that this article content has no conflict of interest.

\section{ACKNOWLEDGEMENTS}

Declared none.

\section{REFERENCES}

[1] Björqvist K. Different names. same issue. Soc Dev 2001; 2: 272-4. [http://dx.doi.org/10.1111/1467-9507.00164]

[2] Archer J. What is Indirect Aggression in Adults? In: Österman K, Ed. Indirect and Direct Aggression. Frankfurt am Main: Peter Lang 2010; pp. 3-16.

[3] Lundh L-G, Daukantaité D, Wångby-Lundh M. Direct and indirect aggression and victimization in adolescents - associations with the development of psychological difficulties. BMC Psychol 2014; 2(1): 43. [http://dx.doi.org/10.1186/s40359-014-0043-2] [PMID: 25566388]

[4] Moroschan G, Hurd PL, Nicoladis E. Sex differences in the use of indirect aggression in adult Canadians. Evol Psychol 2009; 7(2): 146-59. [http://dx.doi.org/10.1177/147470490900700201]

[5] Card NA, Stucky BD, Sawalani GM, Little TD. Direct and indirect aggression during childhood and adolescence: a meta-analytic review of gender differences, intercorrelations, and relations to maladjustment. Child Dev 2008; 79(5): 1185-229. [http://dx.doi.org/10.1111/j.1467-8624.2008.01184.x] [PMID: 18826521]

[6] Dixon R. Rethinking School Bullying: Towards an Integrated Model. Cambridge: Cambridge University Press 2011. [http://dx.doi.org/10.1017/CBO9780511976179]

[7] Kupersmidt JB, Coie JD. Preadolescent peer status, aggression, and school adjustment as predictors of externalizing problems in adolescence. Child Dev 1990; 61(5): 1350-62. [http://dx.doi.org/10.2307/1130747] [PMID: 2245729]

[8] Björkqvist K. Sex differences in physical, verbal, and indirect aggression: a review of recent research. Sex Roles 1994; 30: 177-88. [http://dx.doi.org/10.1007/BF01420988]

[9] Anderson CA, Bushman BJ. Human aggression. Annu Rev Psychol 2002; 53: 27-51. [http://dx.doi.org/10.1146/annurev.psych.53.100901.135231] [PMID: 11752478] 
[10] Berkowitz L. A different view of anger: the cognitive-neoassociation conception of the relation of anger to aggression. Aggress Behav 2012; 38(4): 322-33. [http://dx.doi.org/10.1002/ab.21432] [PMID: 25363699]

[11] Pettit GS, Bates JE, Dodge KA. Supportive parenting, ecological context and children's adjustment: A seven-year longitudinal study. Child Dev 2006; 68: 908-23.

[12] Rothbart MK. Becoming who we are: Temperament and personality in development. New York: Guilford Publication 2011.

[13] Eisenberg N, Spinrad TL, Eggum ND. Emotion-related self-regulation and its relation to childrens maladjustment. Annu Rev Clin Psychol 2010; 6: 495-525.

[http://dx.doi.org/10.1146/annurev.clinpsy.121208.131208] [PMID: 20192797]

[14] Cloninger CR. Completing the psychobiological architecture of human personality development: Temperament, Character, \& Coherence. In: Staudinger UM, Lindenberger UE, Eds. Understanding human development: Dialogues with lifespan psychology. Boston: Kluwer Academic Publishers 2003; pp. 159-82. [http://dx.doi.org/10.1007/978-1-4615-0357-6_8]

[15] Dishion TJ, Nelson SE, Bullock BM. Premature adolescent autonomy: parent disengagement and deviant peer process in the amplification of problem behaviour. J Adolesc 2004; 27(5): 515-30. [http://dx.doi.org/10.1016/j.adolescence.2004.06.005] [PMID: 15475044]

[16] Bowlby J. A Secure Base: Clinical Applications of Attachment Theory. Boston: Taylor and Francis 2005.

[17] Dodge KA, Pettit GS. A biopsychosocial model of the development of chronic conduct problems in adolescence. Dev Psychol 2003; 39(2): 349-71. [http://dx.doi.org/10.1037/0012-1649.39.2.349] [PMID: 12661890]

[18] Liberska H, Farnicka M. The research model of undertaking aggressor or a victim behaviour. Polish Psychological Forum 2014; 18 : 245-55.

[19] Farnicka M, Liberska H, Niewiedzial D. The Psychology of Aggression - chosen problems. Warszawa: PWN 2016.

[20] Białecka - Pikul M. Developmental psychopathology as domain of research on atypical development. Psychologia Rozwojowa 2011; 16: $15-25$.

[21] Cierpiałkowska L, Zalewska M. Psychopathology (Psychopatologia). In: Strelau J, Doliński D, Eds. Psychology. Gdańsk: GWP 2008; pp. 540-50.

[22] Cicchetti DA. Multple- Levels-of Analysis Perspective on Research in Development and Psychopathology. In: Beauchaine TP, Hinshaw SP, Eds. Child and Adolescent Psychopathology Hoboken. New Jersey: Wiley \& Sons 2008; pp. 27-57.

[23] Sroufe A, Duggal S, Weinfeld N, Carlson E. Relationships, development and psychopathology. In: Sameroff A, Lewis M, Miller S, Eds. Handbook of developmental psychopathology. New York: Kluwer Academic/Plenum Publisher 2000; pp. 75-93. [http://dx.doi.org/10.1007/978-1-4615-4163-9_5]

[24] Cicchetti D. Development and Psychopathology. In: Cicchetti D, Ed. Theory and Method. 2nd ed. New York: Developmental Psychopathology: Wiley 2006; pp. 1-23.

[25] Beauchine T, Neuhaus E. Impulsivity and vulnerability to Psychopoathology. In: Beaychine T, Hinshaw S, Eds. Child and adolescent psychopathology. Hoboken, New Jersey: Wiley and Sons 2008; pp. 129-56.

[26] Van Ijzendoorn MH, Sagi A. Cross-Cultural Patterns of Attachment: Universal and Contextual Dimensions. In: Cassidy J, Shaver P, Eds. Handbook of attachment theory and research. New York: Guilford Press 1999; pp. 713-34.

[27] Simons KJ, Paternite CE, Shore C. Quality of parent/adolescent attachment and aggression in young adolescents. J Early Adolesc 2001; 21(2): $182-203$.

[http://dx.doi.org/10.1177/0272431601021002003]

[28] Cole PM, Hall SE. Emotion Dysregulation as a Risk Factor for Psychopathology. In: Beauchaine TP, Hinshaw SP, Eds. Child and Adolescent Psychopathology Hoboken. New Jersey: Wiley \& Sons 2008; pp. 265-99.

[29] Perry B. Child Maltreatment: A neurodevelopmental Perspective on the Role of Trauma and Neglect in Psychopathology. In: Beauchaine TP, Hinshaw SP, Eds. Child and Adolescent Psychopathology Hoboken. New Jersey: Wiley \&Sons 2008; pp. 93-128.

[30] Viljaranta J, Tolvanen A, Aunola K, Nurmi J-E. The developmental dynamics between interest, self-concept of ability, and academic performance. Scand J Educ Res 2014; 58(6): 734-65. [http://dx.doi.org/10.1080/00313831.2014.904419]

[31] Pettit GS, Bates JE, Dodge KA. Supportive parenting, ecological context and children's adjustment: A seven-year longitudinal study. Child Dev 2006; 68: 908-23.

[32] Smith PK. Why has aggression been thought of as maladaptive? In: Hawley P, Little TD, Rodkin PC, Eds. Aggression and Adaptation. London: Lawrence Erlbaum Associates 2007; pp. 65-84.

[33] Crowell SE, Beauchaine TP, Lenzenweger MF. The Development of Bordenline Personality Disorder and Self- Injurious Behavior. In: Beauchaine TP, Hinshaw SP, Eds. Child and Adolescent Psychopathology Hoboken. New Jersey: Wiley \& Sons 2008; pp. 510-41.

[34] Cloninger CR. Temperament and personality. Curr Opin Neurobiol 1994; 4(2): 266-73. [http://dx.doi.org/10.1016/0959-4388(94)90083-3] [PMID: 8038587] 
[35] Olweus D. Stability of aggressive reaction patterns in males: a review. Psychol Bull 1979; 86(4): 852-75. [http://dx.doi.org/10.1037/0033-2909.86.4.852] [PMID: 482487]

[36] Booth-Laforce C, Oxford ML. Trajectories of social withdrawal from grades 1 to 6: prediction from early parenting, attachment, and temperament. Dev Psychol 2008; 44(5): 1298-313.

[http://dx.doi.org/10.1037/a0012954] [PMID: 18793064]

[37] Farnicka M, Grzegorzewska I. Intrapersonal correlates of aggression in adolescents: determinants of undertaking the role of the perpetrator and the victim. Curr Issues Pers Psychol 2015; 3: 25-35. [http://dx.doi.org/10.5114/cipp.2015.49940]

[38] Grzegorzewska I, Farnicka M. Attachment and the risk of mental health disorders during adolescence. Health Psychol Rev 2016; 4: 8-15. [http://dx.doi.org/10.5114/hpr.2016.54545]

[39] Österman K. The Mini Direct Indirect Aggression Inventory. In: Österman K, Ed. Indirect and Direct Aggression, Frankfurt am Main Berlin. Bern: Peter Lang 2010; pp. 103-11. [http://dx.doi.org/10.3726/978-3-653-00716-9]

[40] Armsden GC, Greenberg MT. The Inventory of Parent and Peer Attachment: Relationships to well-being in adolescence. J Youth Adolesc 1987; 16: 427-54

[http://dx.doi.org/10.1007/BF02202939] [PMID: 24277469]

[41] Buss AH, Plomin R. EAS Temperament Questionnaire (polish version Oniszczenko W). Warszawa: Wyd. Pracownia Testów Psychologicznych Polskiego Towarzystwa Psychologicznego 1997.

[42] Buss AH, Perry M. The aggression questionnaire. J Pers Soc Psychol 1992; 63(3): 452-9. [http://dx.doi.org/10.1037/0022-3514.63.3.452] [PMID: 1403624]

[43] Björkqvist K. Lagerspetz K, Österman K DIAS The Direct and Indirect Aggression Scale. Åbo: Åbo Akademi University 1992.

[44] Busching R, Krahé B. The girls set the tone: gendered classroom norms and the development of aggression in adolescence. Pers Soc Psychol Bull 2015; 41(5): 659-76. [http://dx.doi.org/10.1177/0146167215573212] [PMID: 25742920]

[45] Renken B, Egeland B, Marvinney D, Mangelsdorf S, Sroufe LA. Early childhood antecedents of aggression and passive-withdrawal in early elementary school. J Pers 1989; 57(2): 257-81. [http://dx.doi.org/10.1111/j.1467-6494.1989.tb00483.x] [PMID: 2769557]

[46] Bee H. The Developmental Psychology of Human. Poznań: Zysk i S-ka 2004

[47] Cheung-Blunden V, Blunden B. The emotional construal of war: anger, fear, and other negative emotions. Peace Conflict 2008; 14: 123-50. [http://dx.doi.org/10.1080/10781910802017289]

[48] Berzonsky MD. Forming a personal sense of identity in the contemporary world: Challenges and difficulties. Psychologia Rozwojowa 2009; 14(4): 9-20.

[49] Oleszkowicz A, Senejko A. The Psychology of Adolescence (Psychologia dorastania). Warszawa: PWN 2013.

[50] Obuchowska I. The Routes of Adolescence (Drogi Dorastania). Poznań: Media Rodzina 2003.

(C) Marzanna Farnicka; Licensee Bentham Open

This is an open access article licensed under the terms of the Creative Commons Attribution-Non-Commercial 4.0 International Public License (CC BY-NC 4.0) (https://creativecommons.org/licenses/by-nc/4.0/legalcode), which permits unrestricted, non-commercial use, distribution and reproduction in any medium, provided the work is properly cited. 